\title{
Editorial
}

\section{Welcome Message From the New Editor-in-Chief}

\author{
Vicente Cassepp-Borges ${ }^{*_{1}}$ (]
}

[1] Institute of Human and Social Sciences of Volta Redonda, Federal Fluminense University, Volta Redonda, RJ, Brazil.

Interpersona, 2021, Vol. 15(1), 1-2, https://doi.org/10.5964/ijpr.6787

Published (VoR): 2021-06-30.

*Corresponding author at: Universidade Federal Fluminense, Instituto de Ciências Humanas e Sociais de Volta Redonda. Rua Des. Ellis Hermydio Figueira, 783, Bloco A, sala 214-A - Bairro Aterrado, Volta Redonda - RJ, Brazil. CEP 27213-145. E-mail: cassepp@gmail.com

\footnotetext{
(C) This is an open access article distributed under the terms of the Creative Commons Attribution 4.0 International License, CC BY 4.0 (https://creativecommons.org/licenses/by/4.0/), which permits unrestricted use, distribution, and reproduction in any medium, provided the original work is properly cited.
}

I want to proudly introduce the first issue of volume 15 of Interpersona: an International Journal on Personal Relationships, the first one published under my edition. To assume Interpersona as editor-in-chief is, on the one hand, a great satisfaction and, on the other hand, a huge challenge. As a young researcher, I am very honored to take on a successful project already consolidated. During its previous 14 years, the journal featured articles from 90 countries on all continents, being truly international and interdisciplinary. We are one of the main vehicles in the world for spread the international scientific knowledge in interpersonal relationships.

I also register my deep admiration for the academic trajectory of Prof. Dr. Agnaldo Garcia, who founded Interpersona, starting from scratch, in a country with difficulties in obtaining resources. His dedication placed the magazine at the highest levels. I want to thank Prof. Dr. Agnaldo Garcia for his confidence in my work and the potential to occupying such challenging and prestigious position. ${ }^{1}$

I would like to especially thank the PsychOpen GOLD team in Germany, which has been providing essential support for the execution of this work. The dedication and kindness to the editorial team, in the people of Armin Günther, Gerhard Eilbacher and Jurgita Kasteckiene, has been formidable. The support of PsychOpen GOLD platform is what makes Interpersona free and with open access, as all science should be. I also extend my thanks to the two editorial assistants in Brazil, Anelise da Costa Andrade and Maria Sílvia Paolucci de Paiva, who are developing a qualified job in the editorial process.

To assume a major journal, such as Interpersona, is different off to assume a journal at the beginning. To maintain the legacy left by Prof. Agnaldo Garcia can be harder than make a Journal grow. I'm sure we have an

\footnotetext{
1) The invitation came when I decided to organize the IV Brazilian Congress on Interpersonal Relationships Research, held in October 2020. The talks of this congress (in Portuguese) are available online: https://youtu.be/yqikOWwhvEc (Day 1), https://youtu.be//swEubDa06U (Day 2), https://youtu.be/o2Ss5_8VIrl (Day 3). Prof. Dr. Agnaldo Garcia hosted the first three editions of this congress.
} 
excellent team, authors, reviewers and readers. All my effort will be, in the coming years, to develop a job to match Interpersona. I am excited with this challenge.

Enjoy your reading.

Vicente Cassepp-Borges

Editor-in-chief of Interpersona 